\title{
A Linguistic Needs Analysis for EFL at the University Level
}

Teresa Morell Moll

Universidad de Alicante

\begin{abstract}
This paper deals with determining the linguistic competence of university students in EFL classes that are part of an English Studies degree. It suggests a language deficiency analysis (i.e., a combination of their target situation and their actual situation) to aid in the selection of language content to be taught. The proposed needs analysis makes use of the Oxford Placement Test (OPT), which is described as a sound standardized test for university EFL classes. The results obtained by students in the English Studies Department at the University of Alicante are used to explain how the OPT can be used to determine the students' linguistic competence, their language knowledge, their linguistic needs and their progress in linguistic competence.
\end{abstract}

\section{Introduction}

Foreign language teachers have always been confronted with the predicament of providing their students with an appropriate syllabus for language development. Deciding on what to teach and how to teach it have been our main concerns. Yet in order to determine what is to be taught and how to go about it, we must first carry out a needs analysis. Nunan (1988: 5,1996: 24) has suggested that the starting point for a syllabus design can be an analysis of the language, information about the learner, beliefs about the learning process itself, or a combination of these. Although a combination of the three perspectives (linguistic, learner, and learning) would be the most thorough, in this paper I will only focus on an analysis of the language as a departure point for a syllabus design for 
university EFL classes, since the focus of academic departments of linguistics is the analysis of the language (Dubin and Olshtain 27).

In large university classes, unlike smaller classes, the task of discovering the students' needs is not so simple. The large numbers of students makes it impossible for an individual needs analysis'. Traditionally, university language classes have had a set advanced syllabus for incoming students and we have followed the 'sink or swim' principle. Thus, students have been required to have an advanced level of competence if they wanted to follow the language courses with little difficulty. Consequently, many of the first year students have been discouraged and have either dropped out or ultimately failed the course. This is not to say that we should lower the standards of our university language courses, but on the contrary, we should raise the standards by focusing our classes directly to the students' needs.

To determine the students needs we must first define what is meant by a needs analysis and to choose the most appropriate type of needs analysis for our teaching context. Although there is no set definition for 'needs analysis' within the literature, Richard Berwick (52) states that "in general the skeletal structure of a definition is most often expressed as a gap or measurable discrepancy between a current state of affairs and a desired future state". If we apply this broad definition to university EFL classes, we note that we must determine the students actual language competence (current state of affairs) and establish the ultimate objective for the degree course (desired future state). The final objective of a university EFL degree course is to obtain a proficiency level of competence in the language, thus the desired future state is apparent yet we are left to establish what is their actual language competence.

In so far as needs analysis types are concerned, Richard West (8-12) divides them into the following five categories:

1)Target-situation analysis - establishing the learners' language requirements in the occupational or academic situation they are being prepared for,

2) Deficiency analysis - combines both the target- situation analysis and presentsituation analysis,

3) Strategy analysis - consider what is to be learned and how the learners prefer to learn it,

4) Means analysis - course designer or teacher first identifies the relevant features of the situation and then sees how the positive features can be used to advantage to accomodate what would conventionally be seen as constraints,

5) Language audits - any large scale exercise forming the basis of strategic decisions on language needs and training requirements carried out by companies, institutions, professional sectors or countries.

For our teaching context at the university the deficiency analysis, as will be argued below, is the most appropriate.

As in most universities throughout Spain, at the University of Alicante the 'Examen de Acceso (Selectividad)' scores are the only available indicators related to the incoming students' competence. Unfortunately, these scores do not provide us with any reliable means for measuring linguistic competence, which according to Hutchinson and Waters is an essential factor for the planning of a specialized subject. Furthermore, it is not enough 
to know what needs the students have, but also to determine what they already know so that what they lack can be decided. Consequently, the target proficiency can be matched with the existing proficiency of the learners and the syllabus will be constituted by the lacks. This approach to a needs analysis, described by Hutchinson and proposed in this paper for university English language classes is the Deficiency Analysis (Abbott 99).

A deficiency analysis has also been justified by Robinson and Nelson. Robinson (11) claims that it is possible to build a model of needs analysis on a basis of linguistic competence, taking both target needs and present levels into account. Nelson's model integrates placement testing, needs analysis and materials selection ${ }^{2}$. In Nelson's model, after having conducted the Oxford Placement Test the results are interpreted to design the course to be given. In the study conducted in the English Studies Department at the University of Alicante the OPT was also used to conduct the deficiency needs analysis and to plan the language content of the degree course.

The decision to use the OPT was taken after considering Genesee and Upshur's advice (253) "Using standardized tests effectively calls for an understanding of how they are developed and the qualities of sound standardized tests. The six criteria to use to assess them are: 1) test content and purpose, 2) appropriateness, 3) practicality, 4) user qualities, 5) reliability, and 6) validity. The OPT not only proved to be a sound standardized test, but also useful in the planning of the language content relevant to the learners proficiency level (Brindley 67).The description of the OPT which follows will further justify its soundness and will demonstrate how it can be used to determine the students' linguistic competence by noting the elements that can be considered acquired and the elements which are lacking.

\section{Description of the OPT}

The OPT is divided into a listening and a grammar test. The listening test is primarily a test of reading and listening skills, in which the learner's performance is dependent on knowledge of the sound and writing systems of English ${ }^{3}$. The grammar test consists of structures chosen from detailed research into the content of the most widely-known and used coursebooks. In both the listening and grammar parts, the items were carefully chosen. In the case of the listening test, the items were derived from authentic situations and initially pre-tested on native speakers. The structures tested in the Grammar Test were obtained from analysis of test items used by the University of Cambridge Local Examinations Syndicate, the Royal Society of Arts, the ARELS Examinations Trust, and the British Council, at the different levels encompassed by the Oxford Placement Tests.

Not only have the items been carefully selected, but they have already been used to test many foreign language students around the world. The authors of these tests claim that "The Oxford Placement Tests have proved to be effective initial placement instruments and a reliable means of grading students at all levels from elementary upwards, with a consistent record of predictive validity in respect of examination entry". 
The listening test consists of 100 items derived from a bank of several hundred samples of 'slips of the ear' that have been recorded over a number of years in conversations involving native and non-native speakers of English. The students taking the test are asked to listen carefully in order to pick out the correct answer in terms of phonology and not structural correctness nor semantic plausibility. Each item is heard only once and the 100 items are heard in 10 minutes' time. Below there is a sample of an item in the listening test to illustrate the type of question used.

Example:
Will you get me some
a) soap
b) soup
at the supermarket?

In this example, as in all the others, the student must be conscious of the pronunciation as well as of the corresponding spelling of these words. Note how each of the possible answers would be semantically plausible, but the test entails choosing the word which is enunciated.

\subsection{The grammar test}

In contrast, the grammar test requires the students to decide which option best fits the context of the items. For example,
In warm climate people
a) like
b) likes
c) are liking sitting outside in the sun.
If it is very hot, they sit
a) at
b) in
c) under
the shade.

As in this example, many of the items are contextualized or thematically linked. The student must be consciously or subconsciously aware of grammatical rules in order to deduce the correct answers in this part of the test. The grammar test also consists of 100 items which must be answered in fifty minutes' time.

\section{Determining linguistic competence}

The students' language competence is assessed by adding the scores obtained in the two tests (Listening Total=100 Grammar Total=100). The total score represents the level of proficiency ranging from absolute beginner to native speaker (functionally bilingual). For instance, a score from 0-80 is indicative of an absolute beginner, whereas a score of 200 corresponds to a native speaker. In table 1 the interpretation of the scores is shown together with the results of students enrolled in the English language courses(I, II, III, \& IV) at the University of Alicante. 


\begin{tabular}{|c|c|c|c|c|}
\hline OPI Scotes & Eng. I & Eng. II & Eng. III & Eng. IV \\
\hline 0.80 Absolute Beginners & 28 & & & \\
\hline 80.90 Talse Beginners: Minimal Users & 20 & 1 & & \\
\hline 90-100 Basie: Very Limited Users & 27 & 1 & & \\
\hline 100-110 Foundation: Waystage Level & 39 & 3 & & 3 \\
\hline 110-120 Elementary: Limited User & 39 & 15 & 2 & 4 \\
\hline 120-130 Post Elementary: Threshold Level & 38 & 16 & 5 & 9 \\
\hline 130 Pre-Intermediate: Adequate Users & 9 & 10 & 3 & 2 \\
\hline 135 Lower Intermediate & 17 & 10 & 6 & 3 \\
\hline 140 Mid-Intermediate: Independent Users & 12 & 7 & 5 & 9 \\
\hline 145 Upper Intermediate & 7 & 10 & 1 & 7 \\
\hline 150 Post Intermediate: Competent Users & 10 & 16 & 18 & 22 \\
\hline 170 Advanced: Profieient Users & & 1 & 2 & 1 \\
\hline 180 Very Advanced Fighly Proficient User & & & & 1 \\
\hline \multicolumn{5}{|l|}{185 Professional Users } \\
\hline \multicolumn{5}{|l|}{190 Near-native: Expert Users } \\
\hline 200 Native Speakers: Functionally Bilingual & & & & \\
\hline
\end{tabular}

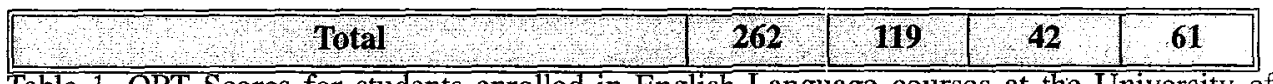

Table 1. OPT Scores for students enrolled in English Language courses at the University of Alicante $^{4}$

The Oxford Placement Test, much like most other system-referenced tests, will determine the students overall mastery of linguistic elements. However, there is always a certain degree of error which must be taken into account. Testing conditions are not always ideal. As stated by Genesee and Upshur (245), the conditions in which a test is given can affect results - for example, the time of day, temperature of the testing room, lighting conditions, noise level, and so on. Test scores can also be affected by how the test taker feels at the time of the test - for example, tired, hungry, angry, and so forth. Distinct testing procedures within the classrooms at the University of Alicante influenced the results obtained. For example, in some classrooms the students filled-in their answers directly onto the computerized sheets, whereas in others they were allowed to transfer their answers from the test paper to the computerized sheet at the end of each test. Thus, the 
grades obtained by the individuals were not exact measurements of their actual competence. Nevertheless, the instructors were roughly able to surmise the range of their students' linguistic competence.

\section{Determing acquired linguistic elements}

The OPT is not only a useful tool for determining the students' general level of competence, but it is also effective in demonstrating the students' mastery of particular linguistic elements. This is made possible through the use of a computer program which calculates the number of correct and wrong responses for each question. At the University of Alicante the Centro de Proceso de Datos has developed a program for optical reading which indicates the number of correct answers, wrong answers and the number of no answers per question.

To determine the acquired linguistic elements for each course I had to designate a certain percentage of correct answers to the given questions. Therefore, I arbitrarily chose $75 \%$ of correct answers as an indicator of group mastery. In other words, all the questions which were answered correctly by at least $75 \%$ of the students were considered as controlled linguistic elements - linguistic elements that the majority were familiar with and had possibly acquired.

In the case of the English I Course very few of the items could be considered as mastered by the group of students. In fact, only 16 of the 100 listening test items and 15 of the 100 grammar test items were answered correctly by at least $75 \%$ of the students. This low percentage of mastery makes us aware of the fact that very few linguistic elements should be assumed as acquired by incoming university students. First year students require a greater exposure to all linguistic items, if they are to carry on in their studies in the English language.

In contrast, in the higher level courses (Eng. II, III, IV) a greater number of items could be considered as mastered by each of the groups. The table below indicates the number of items answered correctly by at least $75 \%$ of the students in each course.

\begin{tabular}{|c|c|c|c|c|}
\hline & Eng. I & Eng. II & Eng. II & Eng. IV \\
\hline Listeming Test Items & 16 & 28 & 27 & 29 \\
\hline Grammar Test Items & 15 & 51 & 58 & 66 \\
\hline
\end{tabular}

Table 2. Items answered correctly by at least $75 \%$ of the students.

As can be seen by the table the grammar items are more indicative of the progress in language acquisition than the listening items. If I had chosen a lower percentage such as $60 \%$ as an indicator of mastery for the listening the figures would be as follows: 


\begin{tabular}{|c|c|c|c|c|}
\hline & Eng. I & Eng. I & Eng. III & Eng. IV \\
\hline Listening Test Items & 44 & 53 & 57 & 62 \\
\hline
\end{tabular}

Table 3. Listening items answered correctly by at least $60 \%$ of the students.

A careful analysis of the items answered correctly by the majority of the students will give us an overall profile of the linguistic elements that have been acquired by the students. For example, a study of the acquired elements from the grammar test for the English I Course reveals that the students have mastered the following language uses:

-present simple to express things which are always true and to refer to mental activities,

-past simple for definite past actions,

-past perfect for earlier past actions,

-future simple in the main clause of first conditional type sentences,

-certain quantifiers: 'any' and 'few',

-superlative adjectives and

-uncountable nouns

In the proceeding language courses the list of acquired language uses included these (mentioned above) and others. The list of acquired linguistic elements increased in relation to the level of the course.

\section{Determining linguistic needs}

So far we have seen how the OPT serves as an indicator of the students' knowledge in the language, but "the target proficiency... needs to be matched against the existing proficicncy of the learner. The gap between the two can be referred to as the learner's lacks" (Hutchinson and Waters 55-56). For our purposes in this study, the learner's lacks will be considered their linguistic needs. The linguistic needs, in other words the grammatical items they have not mastered yet, for the students in each of the language courses can be determined in much the same way as I have calculated the relative mastery of certain linguistic elements. We can determine their needs by calculating the linguistic elements which obtained the most errors among the students of each of the language courses. In my study of the questions with the highest percentage of error, I found that certain linguistic elements caused the most problems among students of all four courses. The following list of linguistic elements are those which had the highest percentage of error in the grammar test:

- nouns used in a general sense e.g. 'man' as in humanity

- use of inversion after certain adverbs e.g. Not only are there ...

- use of specific verb tenses after certain time clauses e.g. It's time we all learnt . .

- use of a gerund after 'to be used to'

In the listening test, I also noted general errors in the distinction between the following phonemes (or an inability to match the sound to the spelling.) 
$-/ d / \& / t /$ as in 'Dennis' and 'tennis'

- /ti / \& /tId/ as in 'committee' and 'committed'

$-/ D / \& / 20 /$ as in 'rod' and 'road'

Nevertheless, if we analyze the questions with the highest percentage of error among the students of each individual course, we can determine which are their particular weaknesses.

\section{Evidence of progress}

Thus far the OPT has proven to be a useful tool to determine the students' overall competence, their acquired linguistic elements and their linguistic needs. Now I would like to take this study a step further and to use the OPT as an indicator of the students progress in linguistic competence. This step can be easily taken by giving the students the test again at the beginning of the next school year. The results of the two tests will then be compared.

\section{Conclusion}

The language deficiency analysis carried out in this study has enabled the verification of competence levels and simultaneously has facilitated the selection of language teaching content. In a defined teaching context it is essential to be aware of the actual situation so that we can approach the intended future situation. Once we know the actual level of competence and the approximate acquired linguistic knowledge, it is easier to determine what are the lacking linguistic elements and in turn the items which should be included within the syllabus. In the English Studies Department at the University of Alicante the OPT has been the tool which has permitted us to evaluate the present situation so that we can lead our students to their ultimate goal of obtaining a proficiency level.

The OPT has proven to be an effective instrument for establishing a needs analysis for incoming students as well as for the students who are enrolled in the upper level language courses. It has not only been used to study individual cases, but also to draw conclusions for entire course levels. It is useful for deciding what linguistic elements should be included in the syllabus of each course.

\section{Notes}

1. Dubin and Olshtain (102) criticize an assessment of individual needs since it could result in multiple course objectives

2.Neison's model has been designed for a business course, i.e for an ESP course. Most needs analysis have been carried out for ESP courses, although the same criteria could be used for a more general course in EFL.

3.The OPT listening test is not the usual type of comprehension test that the students are accustomed to, in fact it is more of a perception test. This could be one of its drawbacks. 
4. This table does not include all the students who are enrolled. It only represents the students who were present on the first day of classes in October 1997. The figures on the table indicate the number of students who obtained the given competence level

\section{Works Cited}

Abbot, G. "Motivation, materials, manpower and methods: some fundamental problems in ESP." ELT Documents, 103, 98-104, 1978.

Allan, D. The Oxford Placement Test. Oxford: Oxford UP, 1992.

Berwick, R. "Needs assessment in language programming: from theory to practice.", The Second Language Curriculum.Ed. Keith R. Johnson. Cambridge: Cambridge UP, 1989. 48 - 62.

Brindley, G. "The role of needs analysis in adult ESL programme design.", The Second Language Curriculum.Ed. Keith R. Johnson. Cambridge: Cambridge UP, 1989. 63 - 78.

Dubin, F. and Olshtain, E. Course Design: Developing Programs and Materials for Language Learning. Cambridge: Cambridge UP, 1986.

Genesee, F. and Upshur, J. Classroom-Based Evaluation in Second Language Education. Cambridge: Cambridge UP, 1996.

Hutchinson, T. and Waters, A. English for Specific Purposes. Cambridge: Cambridge UP, 1987. Nelson, M. A Model for course design in ESP for Business. TESOL dissertation. Manchester: Manchester UP, 1992.

Nunan, D. Syllabus Design. Hong Kong: Oxford UP, 1988. and Lamb, C. The Self-Directed Teacher.Cambridge: Cambridge UP, 1996.

Robinson, P. ESP Today. Hemel Hempstead: Prentice Hall International, 1991.

West, R. "State of the art: Needs Analysis in language teaching" Language Teaching Journal 11994 